\title{
Estimativa da produção microbiana em cabras lactantes alimentadas com diferentes teores de proteína na dieta ${ }^{1}$
}

\author{
Carlos Elysio Moreira da Fonseca ${ }^{2}$, Rilene Ferreira Diniz Valadares ${ }^{3}$, Sebastião de Campos \\ Valadares Filho ${ }^{4}$, Maria Ignez Leão ${ }^{4}$, Paulo Roberto Cecon ${ }^{5}$, Marcelo Teixeira Rodrigues ${ }^{4}$, Douglas \\ dos Santos Pina ${ }^{6}$, Marcos Inácio Marcondes ${ }^{6}$, Mônica Lopes Paixão ${ }^{6}$, Alexandre Magno Araújo ${ }^{7}$
}

\author{
${ }_{1}$ Parte da tese de Doutorado do primeiro autor apresentada à UFV, parcialmente financiada pelo CNPq/FAPEMIG. \\ 2 DPA/IZ/UFRRJ, Seropédica-RJ. \\ ${ }^{3}$ DVT/UFV, Viçosa-MG. \\ ${ }^{4}$ DZO/UFV, Viçosa-MG \\ 5 DPI/UFV, Viçosa-MG. \\ ${ }^{6}$ Pós-graduação em Zootecnia-UFV. \\ 7 Zootecnista.
}

RESUMO - Este trabalho foi conduzido com o objetivo de avaliar a produção microbiana em cabras alimentadas com diferentes teores de PB na dieta. Utilizaram-se 16 cabras lactantes distribuídas em quatro quadrados latinos 4 x 4 , sendo um deles composto por cabras fistuladas alimentadas com diferentes teores de PB $(11,5,13,5,15,5$ e $17,5 \%$ PB na matéria seca) na dieta. Nas cabras fistuladas, realizaram-se coletas de digesta no rúmen e no omaso. Não foi constatada diferença entre as técnicas de estimativa da produção microbiana. Assim, 12 cabras não fistuladas foram utilizadas para avaliação do efeito do teor de PB na dieta sobre a excreção de derivados de purinas, o fluxo de nitrogênio microbiano e a eficiência de síntese microbiana, obtidos a partir de coleta total e de amostras spot de urina. Para estimativa do volume urinário em amostras spot, utilizou-se a excreção média de creatinina na urina, que foi de $26,05 \mathrm{mg}$ por $\mathrm{kg}$ de $\mathrm{PV}$ e não diferiu entre tratamentos. $\mathrm{O}$ volume urinário estimado com o uso de amostras spot foi similar ao observado com a coleta total. Em ambos os casos, houve aumento da quantidade de purinas absorvidas e do fluxo intestinal de nitrogênio microbiano com a elevação do teor de PB na dieta Concluiu-se que a técnica dos derivados de purinas pode ser usada para estimativa da produção microbiana em caprinos e que o uso de amostras spot pode ser uma boa alternativa para se avaliar a produção microbiana em condições de campo.

Palavras chave: caprinos, derivados de purinas, eficiência microbiana

\section{Microbial protein synthesis in lactating goats fed diets with increasing levels of dietary protein}

\begin{abstract}
The objective of this trial was to study the effects of increasing dietary levels of crude protein (CP) on microbial protein synthesis of lactating dairy goats. The microbial markers purines bases and purine derivatives (PD), measured in spot urine samples or in urine samples from total collection, were used to estimate microbial protein synthesis. Sixteen lactating goats (four fitted with ruminal cannula) were randomly assigned to four replicated 4 × 4 Latin squares and were fed the following dietary CP levels [dry matter (DM) basis]: 11.5, 13.5, 15.5 or $17.5 \%$. No significant differences were observed between techniques for estimating microbial protein synthesis. Therefore, 12 non-cannulated goats were used to evaluate the effect of dietary CP level on PD excretion, microbial nitrogen flow and microbial efficiency using either total or spot collection of urine. Because creatinine excretion did not differ among treatments, the average value $26.05 \mathrm{mg}$ of urinary creatinine excreted per $\mathrm{kg}$ of body weight was used for estimating the volume of urine using spot samples. Urinary volume estimated using spot samples was similar to that measured with total urine collection. In both cases, an increase on the amount of absorbed purines was observed when the dietary CP level increased in the diet. In brief, PD can be used for estimating microbial protein synthesis in lactating goats and spot samples were a good alternative for total collection of urine.
\end{abstract}

Key Words: goat, microbial efficiency, purine derivatives

\section{Introdução}

A síntese de proteína microbiana no rúmen atende de 60 a $85 \%$ das exigências para mantença, crescimento, ges- tação e lactação em ruminantes (Timmermans Jr. et al., 2000). Uma dieta formulada para máxima fermentação ruminal pode aumentar o consumo de MS, além de permitir o uso eficiente da proteína degradável no rúmen. A produção de proteína 
microbiana está diretamente relacionada à quantidade de carboidratos fermentáveis, de proteína degradável no rúmen e de minerais ( NRC, 2001).

Diversas técnicas baseadas no uso de indicadores microbianos e de animais fistulados no abomaso ou intestino delgado têm sido utilizadas para avaliação da síntese de compostos nitrogenados microbianos (Egan \& Doyle, 1985). Todavia, estas técnicas são laboriosas e podem comprometer o bem-estar animal, sendo interessante, portanto, o desenvolvimento de métodos não-invasivos para esses fins.

O uso da técnica da excreção urinária de derivados de purinas para determinação da síntese de compostos nitrogenados microbianos proposta por Topps \& Elliot (1965) demonstrou relação direta entre a excreção urinária de metabólitos de purinas e a produção de nitrogênio microbiano em ovelhas. No entanto, maiores progressos no estabelecimento desta técnica têm sido obtidos em bovinos e ovinos (Chen et al., 1995; Valadares et al., 1999).

Para o uso da técnica de derivados de purinas, assume-se que o fluxo intestinal dos ácidos nucléicos é predominantemente de origem microbiana e que, após a digestão intestinal, as bases purinas (adenina e guanina) são absorvidas, catabolizadas e excretadas proporcionalmente na urina. Os derivados de purinas são excretados como hipoxantina, xantina, ácido úrico e alantoína (Yu et al., 2002). Em bovinos, alantoína e ácido úrico são os principais derivados de purinas presentes na urina, em razão da alta atividade no sangue e nos tecidos da enzima xantina oxidase, que converte xantina e hipoxantina em ácido úrico antes da excreção. Caprinos, ovinos e suínos, no entanto, excretam quantidades substanciais de xantina e hipoxantina, em virtude da menor atividade da enzima xantina oxidase no plasma (Chen et al., 1990; Belenguer et al., 2002).

Enquanto vários pesquisadores têm trabalhado com a técnica da excreção diária de derivados de purinas para estimativa do fluxo intestinal de proteína em ovinos e bovinos (Fujihara et al., 1987; Chen et al., 1995; Valadares et al., 1999), poucos têm estudado o uso desta técnica em cabras leiteiras (Lindberg, 1985).

O uso da técnica de derivados de purina na urina requer a coleta total de urina, mas resultados promissores têm sido obtidos com coleta de amostras spot de urina (Chen et al., 1995; Valadares et al., 1999), o que pode simplificar a estimativa da produção de urina em condições de campo.

A creatina é uma substância sintetizada nos músculos e seu metabólito (a creatinina) pode ser excretado pela urina, em função relativamente constante ao peso vivo (Valadares et al., 1997). Por isso, a excreção urinária de creatinina tem sido usada para obtenção da estimativa da produção diária de urina, de derivados de purinas e da produção de proteína bacteriana a partir de amostras spot.

Este trabalho foi conduzido com o objetivo de avaliar o efeito do teor de proteína na dieta sobre a produção de proteína microbiana - estimada por meio das técnicas das bases purinas no omaso e da excreção urinária de derivados de purinas - e a excreção total de derivados de purinas, calculado por meio da coleta total de urina ou de coleta spot de urina.

\section{Material e Métodos}

O experimento foi realizado no Setor de Caprinocultura do Departamento de Zootecnia da Universidade Federal de Viçosa, em Viçosa - MG, no período de 10 de outubro a 10 de dezembro de 2002.

Foram utilizadas 16 cabras da raça Alpina, das quais quatro eram fistuladas no rúmen. Os animais foram mantidos em baias individuais $\left(1,5 \mathrm{~m}^{2}\right)$ com piso ripado de madeira, comedouro, bebedouro e aparato para coleta total de fezes e urina, separadamente. As cabras foram distribuídas em quatro quadrados latinos 4 x 4 . Cada período experimental teve duração de 15 dias.

As cabras foram alimentadas com quatro dietas à base de silagem de milho ( $47 \%$ ) e concentrado ( $53 \%$ ), composto de fubá de milho, farelo de soja, uréia e minerais, formuladas para conter 11,$5 ; 13,5 ; 15,5$ e $17,5 \%$ de $\mathrm{PB}$ na MS total (Tabela 1).

As dietas foram fornecidas às 7 e $16 \mathrm{~h}$, em quantidade suficiente para garantir $15 \%$ de sobras. As coletas de sobras foram feitas do $8^{\circ}$ ao $15^{\circ}$ dia de cada período experimental, sendo conservadas a $-20^{\circ} \mathrm{C}$ para análises posteriores.

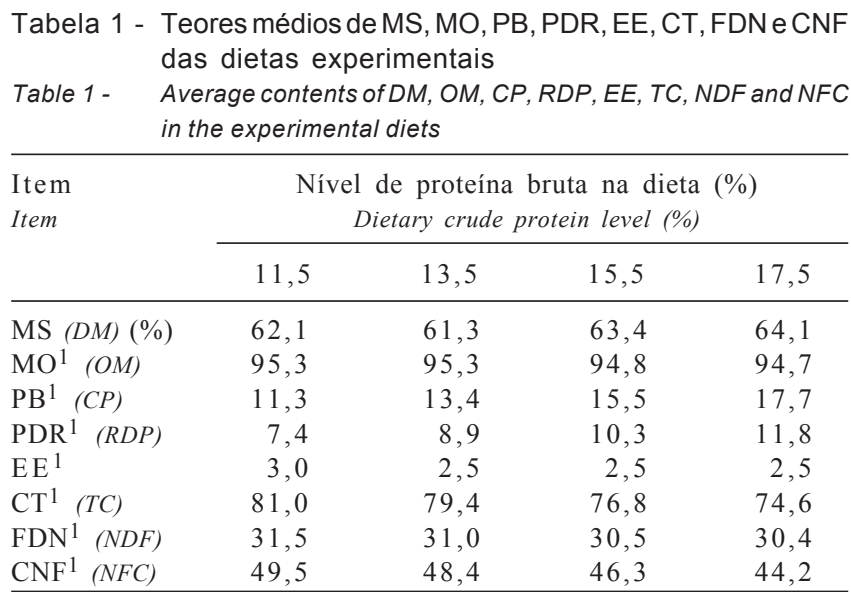

$1 \%$ na MS (\% of DM). 
Apenas as cabras fistuladas foram utilizadas para comparação da produção microbiana, estimada pelas técnicas das bases purinas no omaso, e da excreção urinária total de derivados de purinas.

Além das cabras fistuladas, utilizaram-se também 12 cabras não fistuladas, para determinação da excreção de derivados de purinas, por meio da comparação das técnicas de coleta total e de coleta spot.

Utilizou-se óxido de cromo como indicador externo, fornecido via oral para as cabras fistuladas, durante todo o período experimental, em quantidade diária de $1,5 \mathrm{~g}$, às $12 \mathrm{~h}$.

As coletas de digesta de omaso foram feitas uma vez ao dia, durante três dias, em intervalos de 28 horas, iniciando-se às $8 \mathrm{~h}$ do $8 \underline{\mathrm{o}}$ dia de cada período experimental, obtendo-se aproximadamente $150 \mathrm{~mL}$ de digesta omasal diariamente. As amostras de digesta de omaso foram secas a $65^{\circ} \mathrm{C}$ em estufa de ventilação forçada, durante 96 horas e processadas em moinho com peneira de $1 \mathrm{~mm}$. Amostras compostas, referentes aos três dias de coleta, foram elaboradas com base no peso seco para cada animal em cada período.

As amostras de leite da $1^{\mathrm{a}} \mathrm{e} 2^{\mathrm{a}}$ ordenhas de cada animal foram coletadas no $10^{\mathrm{a}}$ dia de cada período experimental, sendo agrupadas em amostras compostas proporcionais à produção de cada ordenha. Uma alíquota de $10 \mathrm{~mL}$ de cada amostra de leite foi retirada, misturada com $5 \mathrm{~mL}$ de ácido tricloroacético a $25 \%$, filtrada em papel-filtro e armazenada a $-20^{\circ} \mathrm{C}$ para posteriores análises de alantoína.

As coletas totais de urina foram realizadas durante três dias consecutivos, no $11^{\underline{0}}, 12^{\underline{o}}$ e $13^{\underline{o}}$ dias de cada período experimental A urina foi coletada separada das fezes em galões plásticos contendo $100 \mathrm{~mL}$ de $\mathrm{H}_{2} \mathrm{SO}_{4}$ a $20 \%$ e, ao final de cada dia de coleta, foi pesada, homogeneizada e filtrada em gaze, retirando-se uma alíquota de $20 \%$ do volume diário para formação de uma amostra composta por cabra em cada período.

Alíquotas de $10 \mathrm{~mL}$ das amostras compostas foram diluídas em $40 \mathrm{~mL}$ de $\mathrm{H}_{2} \mathrm{SO}_{4}$ a $0,036 \mathrm{~N}$. Estas amostras foram elaboradas com pH inferior a 3 para evitar a destruição bacteriana dos derivados de purinas urinária e a precipitação do ácido úrico. Posteriormente, foram armazenadas a $-20^{\circ} \mathrm{C}$, sendo submetidas às análises de alantoína, xantina e hipoxantina, ácido úrico, creatinina e uréia.

No $14^{\circ}$ dia de cada período experimental, foram coletadas amostras spot de urina, aproximadamente 4 horas após a alimentação, durante micção espontânea. Essas amostras foram processadas da mesma forma que aquelas obtidas em coleta de 24 horas.

Para determinação da composição dos microrganismos, aproximadamente $1 \mathrm{~L}$ de digesta de rúmen de cada animal fistulado foi coletado via fístula ruminal, às 12 horas do 15 - dia do período experimental, e os microrganismos foram separados conforme técnica descrita por Cecava et al. (1990). A estimativa da produção de biomassa microbiana foi feita utilizando-se a técnica das bases purinas, conforme descrito por Ushida et al. (1985).

A quantidade de compostos nitrogenados microbianos presentes no omaso foi estimada pelo fluxo de N-RNA presente no omaso dividido pela relação N-RNA: N-total nos microrganismos isolados do rúmen. $\mathrm{O}$ fluxo de MS bacteriana no omaso foi determinado pela relação entre $\mathrm{o} N$ total presente no omaso e a porcentagem de $\mathrm{N}$ na MS microbiana.

As análises de alantoína, ácido úrico, xantina e hipoxantina na urina e de alantoína no leite foram realizadas pelo método colorimétrico, conforme Chen \& Gomes (1992).

A excreção diária de creatinina, expressa em mg/kg de PV, foi obtida a partir da excreção diária de creatinina de todos os animais, em todos os tratamentos. $\mathrm{O}$ volume urinário usado para estimar a excreção diária de derivados de purinas (DP) das amostras spot de urina foi obtido, para cada animal, multiplicando-se o respectivo PV pela excreção diária média de creatinina em $\mathrm{mg} / \mathrm{L}$ e dividindo-se esse produto pela concentração de creatinina ( $\mathrm{mg} / \mathrm{L})$ na amostra spot de urina.

A excreção total DP foi estimada pela soma das quantidades de hipoxantina e xantina, ácido úrico e alantoína excretadas na urina e da quantidade de alantoína secretada no leite.

A quantidade de purinas microbianas absorvidas (X, $\mathrm{mmol} /$ dia) foi estimada a partir da excreção de derivados de purinas ( $\mathrm{Y}, \mathrm{mmol} / \mathrm{dia})$, por meio das equações propostas por Chen \& Gomes (1992), para ovinos:

$$
\mathrm{Y}=0,84 \mathrm{X}+\left(0,150 \mathrm{PV}^{0,75} \mathrm{e}^{-0,25 \mathrm{X}}\right)
$$

em que Y é a excreção de derivados de purinas ( $\mathrm{mmol} / \mathrm{d})$; e X corresponde às purinas microbianas absorvidas ( $\mathrm{mmol} / \mathrm{d})$.

O fluxo intestinal de $\mathrm{N}$ microbiano ( $\mathrm{g} \mathrm{NM} / \mathrm{d}$ ) foi estimado a partir da quantidade de purinas absorvidas (X mmol/d), segundo a equação de Chen \& Gomes (1992):

$$
\mathrm{NM}(\mathrm{g} / \mathrm{d})=\frac{\mathrm{X}(\mathrm{mmol} / \mathrm{d}) \times 70}{0,116 \times 0,83 \times 1000}=0,727 \mathrm{X}
$$

assumindo-se a digestibilidade de 0,83 para as purinas microbianas, a relação 0,116 de $\mathrm{N}$ purina: $\mathrm{N}$ total e o conteúdo de $\mathrm{N}$ das purinas de $70 \mathrm{mg} \mathrm{N} / \mathrm{mmol}$.

Foram empregadas também as equações propostas por Belenguer et al. (2002), para caprinos, nas quais a quantidade de purinas absorvidas ( $\mathrm{X} \mathrm{mmol} / \mathrm{d}$ ) pode ser estimada como a excreção de derivados de purinas (Y)/taxa de recuperação de purinas $(0,76)$ :

$$
\mathrm{X}=\mathrm{Y} / 0,76
$$


Assumindo que 0,92 é a digestibilidade verdadeira das bases purinas no duodeno e 1,97 (mmol de bases purinas/ g N) a razão entre as bases purinas (164 mmol/g MS) e o conteúdo de $\mathrm{N}(83,8 \mathrm{mg} / \mathrm{g}$ MS) na população microbiana extraída do rúmen de cabras, Belenguer et al. (2002) propuseram a seguinte equação:

$$
\mathrm{NM}(\mathrm{g} / \mathrm{d})=\mathrm{X} /(0,92 \times 1,97)
$$

em que $\mathrm{X}$ corresponde às purinas microbianas absorvidas $(\mathrm{mmol} / \mathrm{d})$.

A matéria orgânica degradada no rúmen (MODR) foi calculada pela diferença entre o consumo de $\mathrm{MO}$ e o fluxo de MO omasal.

Os resultados foram avaliados por meio de análises de variância e de regressão, utilizando-se o Sistema de Análises Estatísticas - SAEG (UFV, 1999). Para comparar as médias dos tratamentos e testar a significância dos coeficientes das regressões, foi utilizado o teste " $\mathrm{t}$ " de Student a 5\% de probabilidade. As técnicas de estimativa da produção microbiana foram comparadas aplicando-se o teste t pareado.

\section{Resultados e Discussão}

A composição média das bactérias do rúmen foi de 80,3\% de MS, 78,2\% de MO e 8,03\% de nitrogênio total, com base na MS, e a relação N-RNA/N-total na MS foi de 0,225.

A produção microbiana e a eficiência microbiana estimadas pela técnica das bases purinas no omaso (Ushida et al., 1985) e pela técnica dos derivados de purinas, segundo as equações propostas por Chen \& Gomes (1992) e por Belenguer et al. (2002), utilizando cabras fistuladas, são apresentadas na Tabela 2. Considerando-se apenas as cabras fistuladas, o fluxo de nitrogênio microbiano no omaso não foi influenciado pelo teor de $\mathrm{PB}$ dietética $(\mathrm{P}>0,1)$. $\mathrm{Na}$ comparação do fluxo de nitrogênio microbiano (NM) pelo teste t pareado, constatou-se que os resultados obtidos pela equação de Chen \& Gomes (1992) foram superiores $(\mathrm{P}<0,01)$ aos obtidos pela equação de Belenguer et al. (2002), de 12,4 e 10,5 g de NM/dia, respectivamente.

Não foi constatada diferença pelo teste $t$ pareado $(\mathrm{P}>0,05)$ entre os resultados obtidos para o fluxo intestinal (11,83 e 12,37 g de NM, respectivamente) pela equação de Chen \& Gomes (1992) e pela técnica de Ushida et al. (1985). Portanto, a técnica de derivados de purinas pode ser adotada para estimativa da produção microbiana em caprinos.

A eficiência de síntese microbiana, avaliada pela técnica de Ushida et al. (1985) e pela técnica dos derivados de purinas (g de $\mathrm{N}$ microbiano/kg de MODR) apresentou resposta linear crescente ao conteúdo de $\mathrm{PB}$ na dieta (Tabela 2).

Considerando que a técnica dos derivados de purina (DP) apresentou resultado semelhante ao obtido pela técnica das bases purinas no omaso, avaliou-se posteriormente a produção microbiana, estimada pela técnica dos derivados de purinas a partir de coletas de urina apenas nas amostras

Tabela 2 - Médias, coeficientes de variação $(C V, \%)$ e determinação $\left(r^{2}\right)$ e equações de regressão ajustadas para o fluxo de NM e para a eficiência de síntese microbiana (EM), estimada pela técnica de Ushida et al. (1985) e pelas equações propostas por Chen \& Gomes (1992) e Belenguer et al. (2002), de acordo com os teores de PB nas dietas

Table 2 - Means, coefficients of variation (CV,\%) and determination $\left(r^{2}\right)$ and adjusted regression equations for microbial nitrogen flow (MN) and for microbial efficiency ( $\mathrm{g}$ microbial $\mathrm{N} / \mathrm{kg}$ organic matter digested in the rumen - OMDR) estimated by Ushida et al. (1985) technique and by the equations proposed by Chen \& Gomes (1992) and by Belenguer et al. (2002) for goats fed increasing dietary CP levels

Nível de PB (\%)

$$
\text { CP level }
$$

\begin{tabular}{llllllll}
\cline { 2 - 3 } Item & 11,5 & 13,5 & 15,5 & 17,5 & CV\% & r $^{2} \quad$ Equação ajustada
\end{tabular}

Produção microbiana (g NM/dia)

Microbial protein synthesis $(M N, g / d)$

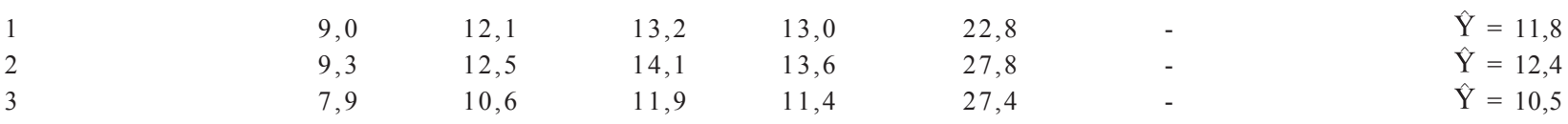

Eficiência de síntese microbiana (g NM/kg MODR)

Microbial efficiency synthesis ( $\mathrm{g}$ microbial N/kg OMDR)

\begin{tabular}{rrrrrrrr}
1 & 9,9 & 13,2 & 13,9 & 14,6 & 17,7 & 0,84 & $\hat{\mathrm{Y}}=2,1+0,744 * \mathrm{~PB}$ \\
2 & 10,4 & 13,4 & 14,5 & 14,8 & 23,9 & 0,85 & $\hat{\mathrm{Y}}=2,74+0,725^{* * *} \mathrm{~PB}$ \\
3 & 8,9 & 11,4 & 12,2 & 12,5 & 23,2 & 0,85 & $\hat{\mathrm{Y}}=2,79+0,583 * * * \mathrm{~PB}$ \\
\hline
\end{tabular}

${ }^{*} e^{* * *}$ significativo a 5 e $10 \%$ de probabilidade, respectivamente, pelo teste $t$

1 - Coletas no omaso (Ushida et al.1985).

2 - Derivados de purinas na urina (Chen \& Gomes, 1992).

3 - Derivados de purinas na urina (Belenguer et al., 2002) 
referentes às 12 cabras não fistuladas alimentadas com diferentes teores de PB na dieta (dados apresentados na Tabela 5) .

O teor de $\mathrm{PB}$ na dieta não influenciou $(\mathrm{P}>0,01)$ a excreção de creatinina, que foi em média $26,05 \mathrm{mg} / \mathrm{kg}$ de $\mathrm{PV}$, o que equivale a $226,5 \mathrm{mmol} / \mathrm{kg}^{0,75}$ ou $9,7 \mathrm{mg}$ de $\mathrm{N}$-creatinina por $\mathrm{kg}$ de PV. Este resultado é um pouco inferior à média de $11 \mathrm{mg}$ de N-creatinina por kg de PV obtida por Lindberg (1985). Apesar da diferença entre as médias, a variação dos resultados, em ambos os trabalhos, se situou entre 8 e $12 \mathrm{mg}$ de N-creatinina/ $\mathrm{kg}$ de PV.

A partir da média da excreção de creatinina, avaliada nas amostras de coleta total de urina, durante um período de 72 horas, e da concentração de creatinina avaliada nas amostras spot de urina, estimou-se o volume de urina excretado, que não diferiu ( $\mathrm{P}>0,01)$, pelo teste de t pareado, do volume de urina total observado. Os valores médios e as equações de regressão do volume de urina observado e estimado encontram-se na Tabela 3. Tanto o volume de urina estimado quanto o observado apresentaram comportamento linear crescente com o teor de PB na dieta.

Também foi avaliado o conteúdo de $\mathrm{N}$-uréico nas amostras spot e nas amostras provenientes da coleta total e, em ambos, os casos ocorreu resposta linear crescente $(\mathrm{P}<0,01)$ ao conteúdo de PB na dieta (Tabela 3 ).

Quando expressa em mg/dia e avaliada nas amostras de coleta total, a excreção de alantoína apresentou valores médios de 2072,6; 1970,2; 2603,8 e 2711,5 mg/dia, respectivamente, nos tratamentos com 11,$5 ; 13,5 ; 15,5$ e $17,5 \%$ de PB. Nas amostras spot, obtiveram-se valores médios de $2.905,4,2.842,9,2.842,9$ e $3.435,0 \mathrm{mg} / \mathrm{dia}$. Estas observações situam-se dentro do intervalo observado por Lindberg
(1985), que obteve valores de 2.000 a 5.000 mg de alantoína por dia em pesquisa realizada com cabras leiteiras. Entretanto, esse autor não avaliou a excreção de ácido úrico, xantina e hipoxantina.

As excreções observadas e estimadas de alantoína, ácido úrico, xantina e hipoxantina e derivados de purina, respectivamente, a partir de amostras de coleta total e de amostras spot de urina, são descritas na Tabela 4. Mesmo ocorrendo aumento na quantidade de alantoína excretada com o aumento do teor de PB na dieta, houve decréscimo da contribuição relativa da alantoína à medida que a excreção total de DP aumentou $(\mathrm{P}<0,01)$, resultado divergente do obtido por Chen et al. (1995), que observaram o inverso em ovinos que excretaram proporção de alantoína crescente e de ácido úrico e xantina mais hipoxantina decrescente à medida que a excreção total de derivados de purina aumentou. Possivelmente essa diminuição no percentual de alantoína foi provocada pelo aumento menor na quantidade de alantoína em relação ao aumento dos demais derivados de purinas.

Comparando-se pelo teste t pareado, as quantidades observadas e estimadas de derivados de purinas excretados, não foi constatada diferença entre a quantidade observada (coleta total) e a quantidade estimada (coleta spot), de 22,55 e $22,91 \mathrm{mmol} / \mathrm{dia}$, respectivamente. Portanto, a coleta spot pode ser usada para estimativa da quantidade de derivados de purinas excretados.

A porcentagem média de alantoína excretada variou de 64,5 a 75,9 nas amostras de coleta total e de 73,9 a 85,2 nas amostras de coleta spot. Considerando o valor observado por meio da coleta total e o estimado pela coleta spot, a proporção média relativa de ácido úrico variou entre 9,6 e

Tabela 3 - Médias, coeficientes de variação $(C V, \%)$ e determinação $\left(r^{2}\right)$ e equações de regressão ajustadas para os volumes de urina e as excreções urinárias de $\mathrm{N}$-uréico observados (Obs) e estimados (Est), de acordo com os teores de PB nas dietas

Table 3 - Means, coefficients of variation $(C V, \%)$ and determination $\left(r^{2}\right)$ and adjusted regression equations for the urine volumes and for observed (Obs) and estimated (Est) urinary excretions of urea $\mathrm{N}$ for goats fed increasing dietary CP levels

\begin{tabular}{|c|c|c|c|c|c|c|c|}
\hline \multirow[b]{2}{*}{ Item } & \multicolumn{4}{|c|}{$\begin{array}{c}\text { Nível de PB (\%) } \\
\text { CP level }\end{array}$} & \multirow[b]{2}{*}{$\mathrm{CV} \%$} & \multirow[b]{2}{*}{$\mathrm{r}^{2}$} & \multirow[b]{2}{*}{$\begin{array}{l}\text { Equação ajustada } \\
\text { Adjusted equation }\end{array}$} \\
\hline & 11,5 & 13,5 & 15,5 & 17,5 & & & \\
\hline \multicolumn{8}{|c|}{$\begin{array}{l}\text { Volume urinário }(\mathrm{L} / \mathrm{dia}) \\
\text { Urinary volume }(\mathrm{L} / \mathrm{d})\end{array}$} \\
\hline Obs & 0,79 & 0,99 & 1,38 & 1,45 & 35,9 & 0,94 & $\hat{\mathrm{Y}}=-0,569+0,119 * * \mathrm{~PB}$ \\
\hline Est & 0,78 & 1,01 & 1,38 & 1,47 & 34,1 & 0,96 & $\hat{\mathrm{Y}}=-0,619+0,122 * * \mathrm{~PB}$ \\
\hline \multicolumn{8}{|c|}{$\begin{array}{c}\text { Excreção urinária de } \mathrm{N} \text { uréia }(\mathrm{g} / \mathrm{dia}) \\
\text { Urinary excretion }(\mathrm{g} / \mathrm{d})\end{array}$} \\
\hline Obs & 4,42 & 6,21 & 9,59 & 12,69 & 29,0 & 0,98 & $\hat{\mathrm{Y}}=-12,216+1,409 * * \mathrm{~PB}$ \\
\hline Est & 5,32 & 8,00 & 12,27 & 17,80 & 45,0 & 0,98 & $\hat{\mathrm{Y}}=-19,369+2,084 * * \mathrm{~PB}$ \\
\hline
\end{tabular}

** Significativo a $1 \%$ de probabilidade, pelo teste $\mathrm{t}$.

** Significant at $1 \%$ of probability, by t test. 
Tabela 4 - Médias, coeficientes de variação $(C V)$ e determinação $\left(r^{2}\right)$ e equações de regressão ajustadas para as excreções observadas (obs) e estimadas (est) de alantoína, ácido úrico, xantina e hipoxantina e derivados de purinas, de acordo com os teores de PB na dieta

Table 4 - Means, coefficients of variation (CV,\%) and determination $\left(r^{2}\right)$ and adjusted regression equations for observed (Obs) and estimated (Est) excretions of allantoin, uric acid, xanthine and hypoxanthine and purine derivatives for goats fed increasing dietary CP levels

\begin{tabular}{|c|c|c|c|c|c|c|c|}
\hline \multirow[b]{2}{*}{ Item } & \multicolumn{4}{|c|}{$\begin{array}{c}\text { Nível de PB (\%) } \\
\text { CP level }\end{array}$} & \multirow[b]{2}{*}{$\mathrm{CV} \%$} & \multirow[b]{2}{*}{$\mathrm{r}^{2}$} & \multirow[b]{2}{*}{$\begin{array}{l}\text { Equação ajustada } \\
\text { Adjusted equation }\end{array}$} \\
\hline & 11,5 & 13,5 & 15,5 & 17,5 & & & \\
\hline \multicolumn{8}{|c|}{$\begin{array}{c}\text { Alantoína na urina } \\
\text { Urinary allantoin }\end{array}$} \\
\hline Obs $(\mathrm{mmol} / \mathrm{d})$ & 12,9 & 12,2 & 16,2 & 16,9 & 21,8 & 0,78 & $\hat{\mathrm{Y}}=2,943+0,80 * * \mathrm{~PB}$ \\
\hline Est $(\mathrm{mmol} / \mathrm{d})$ & 16,6 & 16,8 & 16,3 & 19,4 & 53,4 & - & $\hat{\mathrm{Y}}=17,299$ \\
\hline Obs $(\%)$ & 75,8 & 70,9 & 69,0 & 64,5 & 12,5 & 0,98 & $\hat{\mathrm{Y}}=96,1-1,654^{* *} \mathrm{~PB}$ \\
\hline Est $(\%)$ & 85,2 & 80,6 & 73,9 & 76,7 & 9,9 & 0,72 & $\hat{\mathrm{Y}}=102,31-1,6^{* * \mathrm{~PB}}$ \\
\hline \multicolumn{8}{|c|}{$\begin{array}{l}\text { Ácido úrico } \\
\text { Uric acid }\end{array}$} \\
\hline Obs $(\mathrm{mmol} / \mathrm{d})$ & 3,0 & 2,9 & 3,8 & 4,9 & 54,8 & 0,84 & $\hat{\mathrm{Y}}=-1,1+0,33^{* *} \mathrm{~PB}$ \\
\hline Est $(\mathrm{mmol} / \mathrm{d})$ & 1,8 & 2,5 & 4,7 & 4,6 & 69,4 & - & $\hat{\mathrm{Y}}=3,39$ \\
\hline Obs $(\%)$ & 16,6 & 16,2 & 15,5 & 19,9 & 39,3 & - & $\hat{Y}=17,033$ \\
\hline Est $(\%)$ & 9,6 & 11,8 & 19,4 & 17,1 & 59,8 & 0,72 & $\hat{\mathrm{Y}}=-7,25+0,499 * * \mathrm{~PB}$ \\
\hline \multicolumn{8}{|c|}{$\begin{array}{l}\text { Xantina e hipoxantina } \\
\text { Xanthine and hypoxanthine }\end{array}$} \\
\hline Obs $(\mathrm{mmol} / \mathrm{d})$ & 1,2 & 2,4 & 3,8 & 4,9 & 58,1 & 0,96 & $\hat{\mathrm{Y}}=4,575+0,217 * * \mathrm{~PB}$ \\
\hline Est $(\mathrm{mmol} / \mathrm{d})$ & 1,0 & 2,1 & 1,5 & 1,6 & 37,6 & - & $\hat{\mathrm{Y}}=1,542$ \\
\hline Obs $(\%)$ & 7,5 & 12,9 & 15,5 & 15,6 & 47,4 & 0,84 & $\hat{\mathrm{Y}}=-6,6+1,345 * \mathrm{~PB}$ \\
\hline Est $(\%)$ & 5,2 & 7,6 & 6,6 & 6,2 & 59,8 & - & $\hat{Y}=6,427$ \\
\hline \multicolumn{8}{|c|}{$\begin{array}{l}\text { Derivados de purinas } \\
\text { Purine derivatives }\end{array}$} \\
\hline Obs $(\mathrm{mmol} / \mathrm{d})$ & 17,4 & 17,8 & 24,1 & 26,3 & 20,6 & 0,91 & $\hat{\mathrm{Y}}=-2,57+1,654 * * \mathrm{~PB}$ \\
\hline Est $(\mathrm{mmol} / \mathrm{d})$ & 19,6 & 21,6 & 22,7 & 25,9 & 43,5 & 0,96 & $\hat{\mathrm{Y}}=8,068+0,994 * \mathrm{~PB}$ \\
\hline \multicolumn{8}{|c|}{$\begin{array}{l}\text { Alantoína leite } \\
\text { Milk allantoin }\end{array}$} \\
\hline Obs $(\mathrm{mmol} / \mathrm{d})$ & 0,22 & 0,23 & 0,21 & 0,27 & 34,5 & - & $\hat{\mathrm{Y}}=0,23$ \\
\hline
\end{tabular}

** Significativo a $1 \%$ de probabilidade pelo teste $\mathrm{t}$.

** Significant at $1 \%$ of probability, by t test.

$19,9 \%$ e a de xantina e hipoxantina, entre 5,2 e $15,6 \%$. Os resultados foram próximos aos citados para ovinos por Chen \& Gomes (1992), que reportaram as proporções de 60 a $80 \%$ de alantoína, 10 a $20 \%$ de ácido úrico e 5 a $10 \%$ de xantina e hipoxantina. Chen et al. (1990) observaram, em ovinos, que a contribuição relativa de alantoína, ácido úrico exantina e hipoxantina foi, respectivamente, de 55, 33 e 14\%.

Segundo Belenguer et al. (2002), em relação a outras espécies, a excreção basal de derivados de purinas em caprinos parece ser similar à de ovinos. Portanto, procedem as comparações entre as espécies, considerando-se as escassas publicações a respeito de excreção de DP em caprinos.

Belenguer et al. (2002) observaram que a alantoína representou de 80 a $92 \%$ do total de DP excretado por cabras, valor superior ao relatado por Lindberg (1989), que, em estudo com cabritos em aleitamento, observou porcentagens relativas ao total de DP excretados de 54 a $76 \%$ de alantoína, 13 a 33\% de ácido úrico e 10 a 13\% de xantina e hipoxantina, proporções semelhantes às obtidas neste trabalho.

A secreção de alantoína no leite não diferiu $(\mathrm{P}>0,05)$ entre tratamentos e não acompanhou a tendência observada na excreção urinária de alantoína e de derivados de purinas. Portanto, a secreção de alantoína no leite parece não ser um indicador com boa precisão na estimativa da produção microbiana em cabras.

Segundo Yu et al. (2002), as excreções de alantoína, ácido úrico, xantina e hipoxantina podem ser afetadas pelas fontes de proteína dietética e energia, pelos consumos de MS, energia e proteína, pelo peso vivo, pelos aditivos alimentares e pela espécie. Essa afirmação é condizente com os resultados encontrados neste trabalho, pois ocorreu aumento do consumo de MS, PB e NDT com a elevação da PB dietética, enquanto a excreção relativa de alantoína diminuiu e a de ácido úrico e xantina mais hipoxantina aumentou. 
A quantidade de purinas absorvidas (PA) e os fluxos intestinal de nitrogênio microbiano (NM) e de MS microbiana estimados pelas equações de Chen \& Gomes (1992) e Belenguer et al. (2002) são descritos na Tabela 5.

A quantidade de PB (mmol/dia) apresentou comportamento linear crescente conforme o conteúdo de PB de dieta, independentemente da equação utilizada ou da amostra analisada (coleta total ou spot). A estimativa da quantidade de PA pela equação proposta por Belenguer et al. (2002) foi superior $(\mathrm{P}<0,05)$, pelo teste t pareado, à calculada pela equação de Chen \& Gomes (1992) nas amostras de coleta total ou spot.

Apesar de a estimativa da quantidade de PA ter sido superior com o uso da equação de Belenguer et al. (2002), o fluxo intestinal de $\mathrm{N}$ microbiano e de MS microbiana foi superior $(\mathrm{P}<0,01)$, pelo teste t pareado, quando calculado pela equação de Chen \& Gomes (1992). A divergência entre os resultados referentes à quantidade de PA e ao fluxo de $\mathrm{NM}$, obtidos com a equação dos diferentes autores, possivelmente se deve, em parte, à digestibilidade intestinal das bases purinas considerada na elaboração das equações. Chen \& Gomes (1992) e Belenguer et al. (2002) consideram, respectivamente, a digestibilidade de 83 e $92 \%$.

Os fluxos de MS microbiana e N microbiano apresentaram resposta linear crescente ao conteúdo de $\mathrm{PB}$ da dieta. Os valores registrados para o fluxo intestinal de NM foram próximos aos obtidos por Brun-Bellut et al. (1991), que observaram valores de 14,5 a 25,7 g NM/dia, e superiores aos relatados por Cerrillo et al. (1999) e por SotoNavarro et al. (2003), que registraram fluxo de NM de 6,0 a $8,8 \mathrm{~g} \mathrm{NM} / \mathrm{d}$.

Todas as variáveis avaliadas apresentaram resultados semelhantes quando calculados a partir de amostras de coleta total ou coleta spot, como conseqüência do volume urinário similar utilizado nas duas técnicas. Em geral, os resultados obtidos com uso de amostras spot apresentaram tendências semelhantes às observadas em amostras provenientes da coleta total de urina. Portanto, a coleta spot de urina em cabras pode ser uma boa alternativa para estimativa de parâmetros relacionados à técnica dos derivados de purinas em condições em que não haja possibilidade de realização da coleta total de urina. Com a coleta total, a eficiência de síntese microbiana (g NM/kg MODR), calculada com a equação de Belenguer et al. (2002), apresentou resposta positiva ao teor de $\mathrm{PB}$ da dieta (Tabela 6).

Quando se calculou o fluxo de NM pela equação de Chen \& Gomes (1992) nas amostras de coleta total, constatou-se aumento numérico, mas não foi detectada diferença estatística $(\mathrm{P}>0,05)$, assim como reportado por Batista et al.

Tabela 5 - Médias, coeficientes de variação $(C V, \%)$ e determinação $\left(r^{2}\right)$ e equações de regressão ajustadas para a quantidade de purinas absorvidas (PA), em mmol/dia, e o fluxo intestinal de nitrogênio microbiano (NM) e MS microbiana (MSM), em g/dia, de acordo com o teor de PB nas dietas

Table 5 - Means, coefficients of variation (CV,\%) and determination $\left(r^{2}\right)$ and adjusted regression equations for the amount of absorbed purines (AP), expressed in mmol/d, and intestinal flow of microbial nitrogen (MN) and microbial dry matter (MDM), expressed in g/d, for goats fed increasing dietary $\mathrm{CP}$ levels

\begin{tabular}{cccccc}
\hline \multicolumn{9}{c}{ Nível de PB (\%) } \\
CP level
\end{tabular}

\begin{tabular}{|c|c|c|c|c|c|c|c|}
\hline \multirow[b]{2}{*}{$\mathrm{PA}(A P)^{1}$} & \multicolumn{4}{|c|}{$\begin{array}{l}\text { Coleta total } \\
\text { Total collection }\end{array}$} & \multirow[b]{2}{*}{20,6} & \multirow[b]{2}{*}{0,91} & \multirow[b]{2}{*}{$\hat{\mathrm{Y}}=-3,38+2,176^{* *} \mathrm{~PB}$} \\
\hline & 22,9 & 23,5 & 31,7 & 34,6 & & & \\
\hline $\mathrm{PA}(A P)^{2}$ & 20,7 & 21,4 & 28,7 & 30,9 & 21,6 & 0,91 & $\hat{\mathrm{Y}}=-2,13+1,899 * * \mathrm{~PB}$ \\
\hline $\mathrm{NM}(M N)^{1}$ & 12,6 & 13,0 & 17,5 & 19,1 & 20,6 & 0,91 & $\hat{\mathrm{Y}}=-1,867+1,2 * * \mathrm{~PB}$ \\
\hline $\mathrm{NM}(M N)^{2}$ & 15,0 & 15,6 & 20,9 & 22,5 & 21,6 & 0,91 & $\hat{\mathrm{Y}}=-1,549+1,38 * * \mathrm{~PB}$ \\
\hline $\operatorname{MSM}(M D M)^{1}$ & 157,7 & 161,9 & 218,7 & 238,8 & 20,6 & 0,91 & $\hat{\mathrm{Y}}=-23,33+15,01 * * \mathrm{~PB}$ \\
\hline \multirow[t]{2}{*}{$\operatorname{MSM}(M D M)^{2}$} & 187,7 & 194,4 & 260,7 & 280,1 & 21,6 & 0,91 & $\hat{\mathrm{Y}}=-19,36+17,255 * * \mathrm{~PB}$ \\
\hline & \multicolumn{4}{|c|}{$\begin{array}{c}\text { Amostras spot } \\
\text { Spot samples }\end{array}$} & & & \\
\hline PA $(A P)^{1}$ & 24,0 & 25,7 & 28,5 & 31,3 & 43,2 & 0,99 & $\hat{\mathrm{Y}}=9,46+1,238 * \mathrm{~PB}$ \\
\hline $\mathrm{PA}(A P)^{2}$ & 21,7 & 23,3 & 25,5 & 28,3 & 43,5 & 0,99 & $\hat{\mathrm{Y}}=8,56+1,113 * \mathrm{~PB}$ \\
\hline $\mathrm{NM}(M N)^{1}$ & 13,3 & 14,2 & 15,7 & 17,3 & 43,2 & 0,99 & $\hat{\mathrm{Y}}=5,22+0,683 * \mathrm{~PB}$ \\
\hline $\mathrm{NM}(M N)^{2}$ & 15,7 & 16,9 & 18,5 & 20,6 & 79,5 & 0,99 & $\hat{\mathrm{Y}}=6,223+0,809 * \mathrm{~PB}$ \\
\hline $\operatorname{MSM}(M D M)^{1}$ & 165,1 & 176,7 & 196,1 & 215,3 & 43,2 & 0,99 & $\hat{\mathrm{Y}}=65,014+0,85^{*} \mathrm{~PB}$ \\
\hline $\operatorname{MSM}(M D M)^{2}$ & 196,1 & 211,0 & 230,8 & 256,7 & 57,2 & 0,99 & $\hat{\mathrm{Y}}=77,493+1,008 * \mathrm{~PB}$ \\
\hline
\end{tabular}

** $\mathrm{e}^{*}$ significativo, respectivamente, a 1 e $5 \%$ de probabilidade pelo teste $\mathrm{t}$.

1 Belenguer et al. (2002), ${ }^{2}$ Chen \& Gomes (1992).

** and * significant, respectively at 1 and $5 \%$ of probability, by t test. 
Tabela 6 - Médias, coeficientes de variação $(C V, \%)$ e determinação $\left(r^{2}\right)$ e equações de regressão ajustadas para eficiência de síntese microbiana, em g de NM/kg de MODR e em g de PBM/kg de NDT consumido, de acordo com o teor de PB nas dietas

Table 6 - Means, coefficients of variation $(\mathrm{CV}, \%)$ and determination $\left(r^{2}\right)$ and adjusted regression equations for microbial efficiency expressed in $g$ microbial N/kg organic matter digested in the rumen (MN/OMDR) and $g$ of microbial crude protein per kg of TDN (MCP/TDN) consumed, for goats fed increasing dietary CP levels

\begin{tabular}{|c|c|c|c|c|c|c|c|}
\hline \multirow[b]{2}{*}{ Item } & \multicolumn{4}{|c|}{$\begin{array}{l}\text { Nível de PB (\%) } \\
\text { CP level }\end{array}$} & \multirow[b]{2}{*}{$\mathrm{CV} \%$} & \multirow[b]{2}{*}{$\mathrm{r}^{2}$} & \multirow[b]{2}{*}{$\begin{array}{l}\text { Equação ajustada } \\
\text { Adjusted equation }\end{array}$} \\
\hline & 11,5 & 13,5 & 15,5 & 17,5 & & & \\
\hline \multicolumn{8}{|c|}{$\begin{array}{l}\text { Coleta total } \\
\text { Total collection }\end{array}$} \\
\hline NM/MODR $(M N / O M D R)^{1}$ & 13,0 & 13,3 & 16,2 & 17,7 & 22,7 & 0,92 & $\hat{\mathrm{Y}}=2,814+0,843 * * \mathrm{~PB}$ \\
\hline NM/MODR $(M N / O M D R)^{2}$ & 15,5 & 15,9 & 19,3 & 20,5 & 54,5 & - & $\hat{\mathrm{Y}}=17,8$ \\
\hline $\mathrm{PBM} / \mathrm{NDT}(M C P / T D N)^{1}$ & 65,7 & 66,7 & 79,4 & 83,1 & 24,1 & 0,90 & $\hat{\mathrm{Y}}=26,84+3,23 * * \mathrm{~PB}$ \\
\hline $\mathrm{PBM} / \mathrm{NDT}(M C P / T D N)^{2}$ & 69,2 & 71,0 & 83,5 & 85,0 & 25,4 & 0,88 & $\hat{\mathrm{Y}}=33,721+2,997 * * \mathrm{~PB}$ \\
\hline \multicolumn{8}{|c|}{$\begin{array}{c}\text { Amostras spot } \\
\text { Spot samples }\end{array}$} \\
\hline NM/MODR $(M N / O M D R)^{1}$ & 13,6 & 14,4 & 14,8 & 16,3 & 42,1 & - & $\hat{\mathrm{Y}}=14,789$ \\
\hline NM/MODR $(M N / O M D R)^{2}$ & 16,2 & 17,2 & 17,5 & 19,4 & 42,6 & 0,91 & $\hat{\mathrm{Y}}=10,186+0,51 * * * \mathrm{~PB}$ \\
\hline $\mathrm{PBM} / \mathrm{NDT}(M C P / T D N)^{1}$ & 60,7 & 64,1 & 63,9 & 67,4 & 44,6 & - & $\hat{\mathrm{Y}}=64,039$ \\
\hline $\mathrm{PBM} / \mathrm{NDT}(M C P / T D N)^{2}$ & 72,0 & 76,5 & 75,4 & 80,4 & 45,1 & - & $\hat{\mathrm{Y}}=76,068$ \\
\hline
\end{tabular}

* $\mathrm{e}^{\text {** }}$ significativo a 5 e $1 \%$ de probabilidade, respectivamente, pelo teste $\mathrm{t}$.

1 Belenguer et al. (2002), ${ }^{2}$ Chen \& Gomes (1992).

** and * significant, respectively at 1 and $5 \%$ of probability, by t test.

(1994), que não notaram efeito do conteúdo de PB na dieta sobre a eficiência de síntese microbiana, relatando valores entre 11,6 e 16,5 g NM/kg MODR em cabras não-gestantes e não-lactantes.

Os valores médios relativos à eficiência de síntese microbiana obtidos por meio da equação de Chen \& Gomes (1992) foram próximos aos encontrados por Soto-Navarro et al. (2003), de 17,5 e 21,4 g NM/kg de MODR, em cabras alimentadas com teores crescentes de PB fornecidos pelo farelo de soja. Quando avaliada a partir de amostras provenientes da coleta total de urina, a eficiência de síntese microbiana (em g de PBM/kg NDT) apresentou resposta linear crescente $(\mathrm{P}<0,01)$ ao conteúdo de $\mathrm{PB}$ na dieta. Nas amostras spot, a eficiência de síntese microbiana (PBM/ NDT) não foi influenciada pelos tratamentos.

De modo geral, o incremento do teor de proteína nas dietas favoreceu a produção e a eficiência de síntese microbiana. Os valores médios observados de 64 ou $76 \mathrm{~g}$ de $\mathrm{PBM} / \mathrm{kg}$ de NDT foram bastante inferiores ao citado para bovinos pelo NRC (2001), de $130 \mathrm{~g}$ de PBM/ kg de NDT.

\section{Conclusões}

A excreção de derivados de purinas demonstrou ser uma boa técnica para estimativa da produção microbiana em cabras leiteiras.

A coleta spot de urina pode ser utilizada para estimativa da produção e eficiência microbiana.
A secreção de alantoína no leite parece não ser um bom indicador para estimar a produção microbiana em cabras.

O aumento do conteúdo de proteína na dieta proporcionou excreção crescente de derivados de purinas e fluxo intestinal crescente de compostos nitrogenados e matéria seca microbiana.

\section{Literatura Citada}

BATISTA, A.M.V.; COELHO DA SILVA, J.F.; VALADARES FILHO, S.C. et al. Consumo, taxa de passagem e digestão em cabras não-gestantes e não-lactantes e no terço final da gestação. Revista Brasileira de Zootecnia, v.23, n.1, p.149-155, 1994.

BELENGUER, A.; YAÑEZ, D.; BALCELlS, J. et al. Urinary excretion of purine derivatives and prediction of rumen microbial outflow in goats. Livestock Production Science, v.77, p.127-135, 2002

BRUN-BELLUT, J.; KELLY, J.M.; MATHISON, G.W. et al. Effect of rumen degradable protein and lactation on nitrogen metabolism in dairy goats. Canadian Journal of Animal Science, v.71, p.1111-1124, 1991.

CECAVA, M.J.; MERCHEN, H.R.; GAY, L.C. et al. Composition of ruminal bacteria harvested from steers as influenced by dietary energy level, feeding frequency, and isolation techniques. Journal of Dairy Science, v.73, p.2480-2488, 1990.

CERRILLO, M.A.; RUSSEL, J.R.; CRUMP,M.H. The effects of hay maturity and forage to concentrate ratio on digestion kinetics in goats. Small Ruminant Research, v.32, p.51-60, 1999.

CHEN, X.B.; ORSKOV, E.R.; HOVELL, D.B. Excretion of purine derivatives by ruminants: endogenous excretion, differences between cattle and sheep. British Journal of Nutrition, v.63, p.121-129, 1990 .

CHEN, X.B.; GOMES, M.J. Estimation of microbial protein supply to sheep and cattle based on urinary excretion of purine 
derivatives- an overview of technical details. International feed research unit. Aberdeen Rowett Research Institute, 1992. $21 \mathrm{p}$. (Occasional publication).

CHEN, X.B.; MEJIA, A.T.; ORSKOV, E.R. Evaluation of the use of the purine derivative: creatinine ratio in spot urine and plasma samples as an index of microbial protein supply in ruminants: studies in sheep. Journal of Agricultural Science, v.125, p.137-143, 1995.

EGAN, J.K.; DOYLE, P.T. Effect of intraruminal infusion of urea on the response in voluntary feed intake by sheep. Australian Journal of Agricultural Research, v.36, p.483-495, 1985.

FUJIHARA, T; ORSKOV, E.R.; REEDS, P.J. et al. The effect of protein infusion on urinary excretion of purine derivatives in ruminants nourished by intragastric nutrition. Journal of Agricultural Science, v.109, p.7-12, 1987.

LINDBERG, J.E. Urinary allantoin excretion and digestible organic matter intake in dairy goats. Swedish Journal of Agricultural Research, v.15, p.31-37, 1985.

LINDBERG, J.E. Nitrogen metabolism and urinary excretion of purines in goat kids. British Journal of Nutrition, v.61, p.309-321, 1989.

NATIONAL RESEARCH COUNCIL - NRC. Nutrient requirements of dairy cattle. Washington, D.C.: National Academy of Science, 2001. 381p.

SOTO-NAVARRO, S.A.; GOETTSCH A.L.; SAHLU, T. et al. Effects of ruminally degraded nitrogen source and level in a high concentrate diet on site of digestion in yearling Boer $\mathrm{x}$ Spanish wether goats. Small Ruminant Research, v.50, p.117-128, 2003.

TIMMERMANS JR., S.J.; JOHNSON, L.M.; HARRISON, J.H. Estimation of the flow of microbial nitrogen using milk uric acid or allantoin. Journal Dairy Science, v.83, p.1286-1299, 2000.
TOPPS, J.H.; ELLIOT, R.C. Relationship between concentrations of ruminal nucleic acids and excretion of purine derivatives by sheep. Nature, v.205, p.498-499, 1965.

UNIVERSIDADE FEDERAL DE VIÇOSA - UFV. SAEG - Sistema de análises estatísticas. Versão 8,0. Viçosa, MG: 1999. 141p. (Manual do usuário).

USHIDA, K.; LASSALAS, B.; JOUANY, J.P. Determination of assay parameters for RNA analysis in bacterial and duodenal samples by spectrophotometry. Influence of sample treatment and preservation. Reproduction Nutrition Development, v.25, n.6, p. 1037-1046, 1985.

VALADARES, R.F.D.; BRODERICK, G.A.; VALADARES FILHO, S.C. et al. Effect of replacing alfafa silage with high moisture corn on ruminal protein synthesis estimated from excretion of total purine derivatives. Journal of Dairy Science, v. 82, p.2686-2696, 1999.

VALADARES, R.F.D.; GONÇALVES, L.C.; SAMPAIO, I.B. et al. Níveis de proteína em dietas de bovinos 2. Consumo, digestibilidades e balanço de compostos nitrogenados. Revista Brasileira de Zootecnia, v.26, n.6, p.1259-1263, 1997.

YU, P.; EGAN, A.R.; BOON-EK, L. et al. Purine derivative excretion and ruminal microbial yield in growing lambs fed raw and dry roasted legume seeds as protein supplements. Animal Feed Science and Technology, v.95, p.33-48, 2002. 